\title{
A MICRO HEAT EXCHANGER WITH INTEGRATED HEATERS AND THERMOMETERS
}

\author{
Lian Zhang, Shilajeet S. Banerjee, Jae-Mo Koo, Daniel J. Laser, Mehdi Asheghi, \\ Kenneth E. Goodson, Juan G. Santiago, Thomas W. Kenny \\ Department of Mechanical Engineering, Design Division, Stanford University \\ Stanford, CA 94305
}

\begin{abstract}
Two-phase microchannel flow has the potential to remove large heat fluxes from high-performance integrated circuits. More research must study the behavior of microchannel heat exchangers, in particular the impact of small dimensions on bubble formation and the critical heat flux. This work develops microchannel test devices with integrated heaters and thermometers for studying single and two-phase convection. Fabrication techniques include DRIE and silicon-glass anodic bonding. DRIE is used to fabricate rectangular microchannels with a hydraulic diameter less than $100 \mu \mathrm{m}$ in silicon chips. These devices include integrated semiconductor heaters and thermometers and are enabling detailed experiments on single and two-phase forced convective heat removal from microchannels. The heat exchangers remove $25 \mathrm{~W}$ from $2 \mathrm{~cm}^{2}$ area with approximately $50 \mathrm{C}$ average chip temperature rise using $5 \mathrm{ml} / \mathrm{min}$ of DI water, which remains in the liquid state. We observe water boiling in microchannels with a hydraulic diameter of $55 \mathrm{\mu m}$ and a resulting transient temperature fluctuation in the microchannel system. Future work is leveraging and optimizing this experimental structure for imaging bubble formation and for studying the critical heat flux.
\end{abstract}

\section{INTRODUCTION}

The rapid development of high-speed, high-power, highdensity integrated circuits requires compact devices for cooling. Almost 20 years ago, Tuckerman and Pease [1] predicted that single-phase forced convective cooling should be feasible for circuit power densities of more than $1000 \mathrm{~W} / \mathrm{cm}^{2}$, under large flow rates (above $600 \mathrm{ml} / \mathrm{min}$ ). Since then, microchannel heat exchangers have been under constant research interest. Modeling and optimization of single-phase heat exchangers were wellstudied [2-3], while theoretical and experimental studies on twophase flow in microchannels were very limited. Peng et al. [4] investigated flow transition and heat transfer in V-shaped microchannels with a hydraulic diameter ranging from 200-600 $\mu \mathrm{m}$. Jiang et al. [5] studied phase change in diamond-shaped microchannels with hydraulic diameters less than $100 \mathrm{\mu m}$. However, data interpretation in the previous research was impaired by a lack of detailed information about the rate of heat transfer into the fluid and the two-phase flow conditions inside the microchannels. Whether saturated nucleate boiling can or cannot occur in microchannels under $100 \mu \mathrm{m}$ hydraulic diameter remains unknown.

The present work develops parallel-flow microchannel heat exchangers with integrated heaters and thermometers. This work is part of an ongoing effort to experimentally study both temperature distribution and heat transfer rates in microchannels. In our system, glass channel cover slips make it possible to directly observe the flow conditions inside the microchannels. Channels of $50-100 \mu \mathrm{m}$ width and $50 \mu \mathrm{m}$ depth are micromachined into a $2 \mathrm{~cm}$ by $6.5 \mathrm{~cm}$ silicon chip with an effective cooling area of $4 \mathrm{~cm}^{2}$ or $2 \mathrm{~cm}^{2}$. Heaters and thermometers are formed by ion implantation on the backside of the same chip to provide precise heat flux control as well as temperature distribution measurements.

\section{DESIGN}

For viscous internal fluid flow, fluid friction causes a pressure drop along the flow direction. For aspect ratios near unity, the pressure drop $\Delta P$ associated with this single-phase flow can be calculated from [6]

$$
\Delta P=\rho \cdot \frac{64}{\operatorname{Re}} \cdot \frac{L V^{2}}{2 D_{H}}
$$

where $\rho$ is the density of the fluid, Re is the Reynolds number, $L$ is the length of the channel, $V$ is the flow velocity, and $D_{H}$ is the hydraulic diameter of the channel. The Reynolds number can be interpreted as the ratio of the flux of momentum to the viscous force within the channels. For channels in which the flow is predominantly fully developed, which is the case in our work, the pressure drop required to provide a certain mass flow rate is inversely proportional to Re. This relationship causes the pressure gradient along microchannels to be particularly large and, for a given set of dimensions, places an important lower bound on the pressure delivered by the system pump.

The advantage of this large pressure drop is a very high heat removal rate by forced convection. The approximate relationship between the single-phase fluid temperature rise along the microchannels $\Delta T_{W}$ and the heat rate input $q$ is given by

$$
q=\dot{m} c_{p} \Delta T_{W}
$$

where $\dot{m}$ is the fluid mass flow rate, and $c_{p}$ is the fluid specific heat. Because of the higher fluid temperature near the exit, the local chip temperature also increases along the length of the channel. The increase in chip temperature along the channel length is reduced by conduction in the silicon, which augments the heat flux into the fluid near the inlet. However, the total heat rate is related to the average chip and fluid temperatures in

$$
q=h A\left(T_{C, \text { ang }}-T_{W, \text { ang }}\right)
$$

where $h$ is a length-averaged convection coefficient, $A$ is the total wetted area, $T_{C, a v g}$ and $T_{W, a v g}$ are average chip and fluid temperatures respectively. The convection coefficient $h$ can be increased by a factor of 100 to 1000 with forced convection, and under the assumption of uniform heating, it is independent of flow velocity in fully developed laminar flow, which has a Re number less than about 2300 [6].

Using implanted resistors as heaters and thermometers, the heat input $q$ is determined by

$$
q=U I
$$

where $U$ and $I$ are input voltage and current. Since semiconductor resistors have a temperature coefficient that can be calibrated, the local temperature can be determined from the 
resistance variation of the resistors. Hence we are able to control the heat input to the fluid, as well as to monitor the local and average chip temperature.

Table 1. Design parameters of three types of microchannel heat exchangers.

\begin{tabular}{|l|l|l|l|}
\hline & Type 1 & Type 2 & Type 3 \\
\hline Width $(\mu \mathrm{m})$ & 75 & 50 & 100 \\
\hline Depth $(\mu \mathrm{m})$ & 50 & 50 & 50 \\
\hline Length $(\mathrm{cm})$ & 2 & 2 & 2 \\
\hline Number of channels & 50 & 20 & 30 \\
\hline Effective cooling area $\left(\mathrm{cm}^{2}\right)$ & 4 & 2 & 4 \\
\hline Maximum flow rate $\left(\mathrm{ml} / \mathrm{min}^{2}\right)$ & 10 & 5 & 10 \\
\hline Hydraulic diameter $(\mu \mathrm{m})$ & 60 & 50 & 67 \\
\hline Reynolds number $^{*}$ & 56 & 88 & 79 \\
\hline Pressure drop $^{*}(\mathrm{psi})$ & 19.9 & 53.7 & 20.1 \\
\hline
\end{tabular}

"The Reynolds number and the pressure drop are calculated under the maximum water flow rate of the design type. Water properties are taken at ambient conditions.

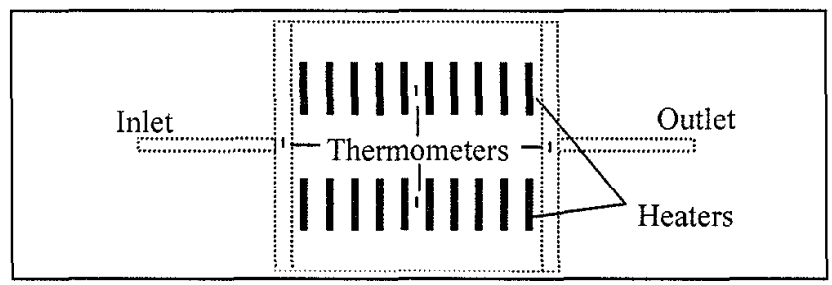

Figure 1. Schematic of the heaters and thermometers. The dashed lines oulline the microchannels (the middle square) and the inlet/outlet on the channel side. On the back side, 20 heater strips are symmetrically distributed over the cooling area, connected in parallel; and 4 separate thermometers are located right at the entrance, exit and two middle spots.

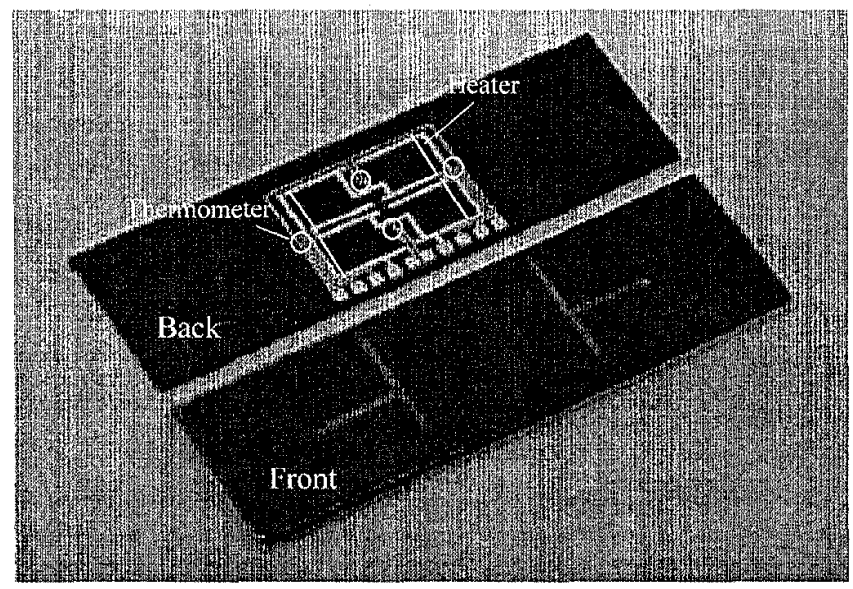

Figure 2. The micro heat exchanger chip. Both the front and back side of the heat exchanger are shown. On the front side, the two " $T$ " shaped channels are $1 \mathrm{~mm}$ wide inlet and outlet, the square between is the effective cooling area, which is $2 \mathrm{~cm}$ by 2 $\mathrm{cm}$ in this device. Locations of heaters and thermometers are marked on the back side.

The design considerations for the system include the pressure drop under the maximum flow rate of $5-10 \mathrm{ml} / \mathrm{min}$, and the resistance and distribution of the heaters and thermometers. We use Equation (1) to calculate the maximum pressure in the system; then estimate the water and chip temperature under a certain heat input rate from Equations (2) and (3); and finally decide the heater resistance based on the desired heat power. On the basis of trial calculations, we have selected three design types, whose parameters are listed in Table 1. Figures 1 and 2 show the layout of the heaters and the thermometers. The resistance of the parallel heaters is $100 \Omega$, while each of the four thermometers has a resistance of $2000 \Omega$.

\section{FABRICATION}

The fabrication process begins the fusion bonding of our own SOI (Silicon-On-Insulator) wafers. First, a pair of $\mathrm{SiO}_{2}$ coated Ntype $\langle 100\rangle$ wafers are placed face to face and self-attached by Van der Waals force. An additional 1-hour annealing at $950 \mathrm{C}$ gives very good fusion bonding. Then we grind the top $\mathrm{Si}$ wafer to a desired thickness of $50 \mu \mathrm{m}$. Second, heaters and thermometers are implanted from the support wafer side (backside). Because the parallel design of the heaters greatly lowers the total heater resistance, the heaters and the thermometers are implanted together. The implant dose is le14 Boron at $40 \mathrm{keV}$. Since the heaters are operated under high power conditions, a long annealing time is necessary (we recommend 6 hours at $1150 \mathrm{C}$ ). The target surface resistivity after annealing is $200 \Omega$ per square. Third, aluminum tracks and pads are deposited to make electrical connections. Fourth, DRIE is used to etch the channels from the SOI side, and then to etch the two inlet/outlet through holes from the backside (shown as dashed rectangle in Figure 3(C)--these are not in the same plane). And finally, a Pyrex7740 glass piece is anodically bonded to the front microchannel side to seal the channels.

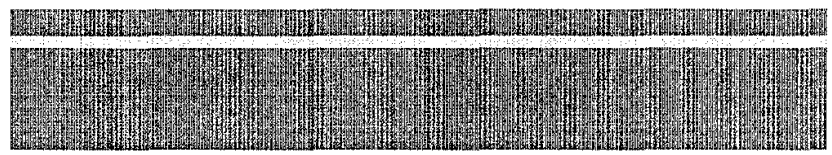

(a) Fusion bonding SOI wafers

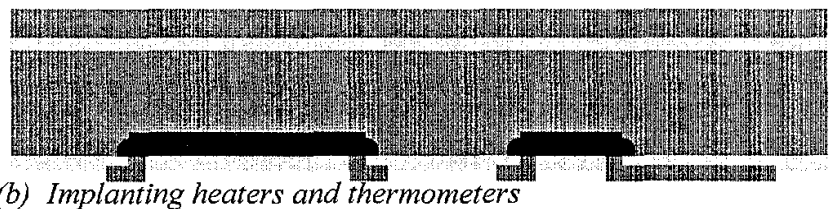

(b) Implanting heaters and thermometers

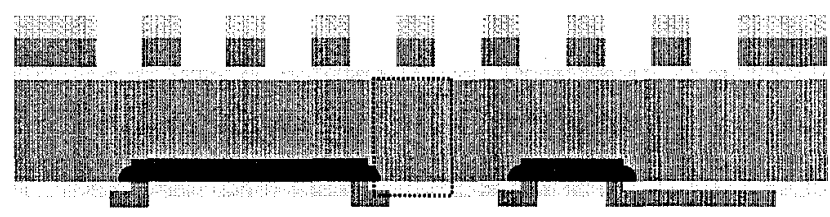

(c) DRIE etching channels and inlet/outlet holes (dashed rectangle)

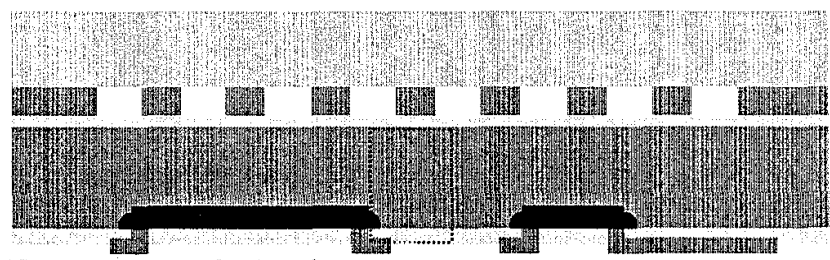

(d) Si-glass anodic bonding

Figure 3. Schematic of fabrication process. 


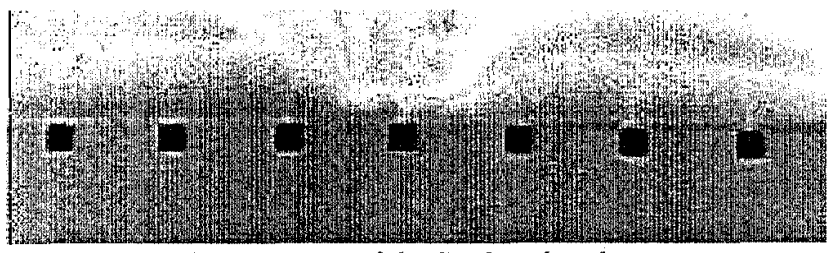

Figure 4. An SEM picture of the Si-glass bonding cross section.

\section{EXPERIMENTAL SETUP}

Fig. 5 shows the experimental setup. A fixture was developed to simplify the exchange of test devices. The fixture has internal flow directors and O-rings to securely seal the inlet and outlet holes in the heat exchanger. It also allows us to etch the inlet and outlet holes from silicon side, which is much easier than from glass side.

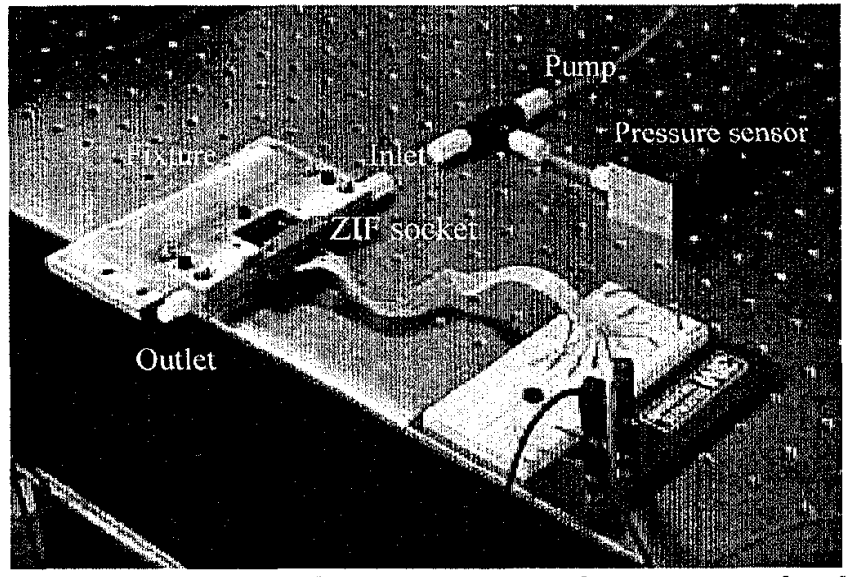

Figure 5. Experimental setup. The test chip is supported and sealed by the fixture with internal flow directors. The ZIF socket connects the heaters and thermometers to the breadboard, where input power is supplied and the thermometer resistances are measured. A pressure transducer is attached at the inlet. The outlet fluid temperature is measured by a thermocouple.

As shown in Figure 6, we attach a surfboard (the breadboarding medium for surface mount) to the resistor side of the heat exchanger, and wire-bond the aluminum pads to the surfboard, which has 10 standard single-in-line pins. We insert

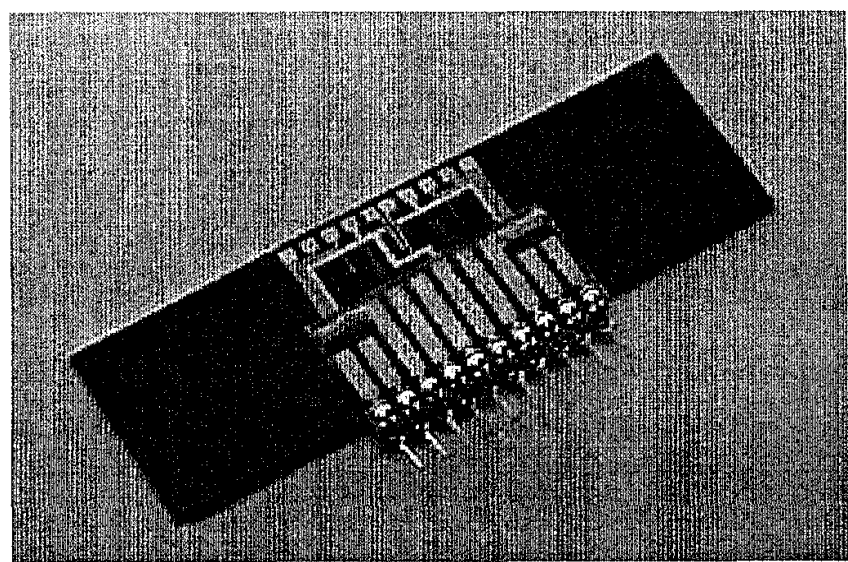

Figure 6 The wire-bonded surfboard and the heat exchanger. the heat exchanger to the fixture, then clamp the ZIF (ZeroInsertion-Force) socket to the surfboard, and thermometer resistances can be measured from the bread board. A pressure sensor located right at the connection of the pump monitors the pressure drop. Since the exit of the fixture is open to the air, the pressure readout at the inlet can be considered the pressure drop along the microchannels. We also have a thermocouple at the outlet to measure the fluid temperature.

\section{EXPERIMENTAL RESULTS}

Six heat exchangers of three types listed in Table 1 were fabricated and tested in our experiments. DI water was used as cooling fluid. Because of the fabrication tolerance, the micromachined channels may not have the exact values as designed in Table 1. The measured actual dimensions of the testing devices are listed in Table 2.

Table 2. Actual dimensions of testing heat exchangers.

\begin{tabular}{|l|l|l|l|l|l|l|}
\hline Device number & 1 & 3 & 4 & 5 & 6 & 7 \\
\hline Type & 1 & 3 & 1 & 3 & 2 & 2 \\
\hline Width (um) & 75 & 100 & 80 & 100 & 55 & 55 \\
\hline Depth (um) & 50 & 50 & 42 & 42 & 42 & 45 \\
\hline Length (cm) & 2 & 2 & 2 & 2 & 2 & 2 \\
\hline $\begin{array}{l}\text { Number of } \\
\text { channels }\end{array}$ & 50 & 30 & 50 & 30 & 20 & 20 \\
\hline $\begin{array}{l}\text { Hydraulic } \\
\text { diameter (um) }\end{array}$ & 60 & 67 & 55 & 59 & 48 & 49 \\
\hline
\end{tabular}

Thermometers on the same chip usually have similar but not identical resistance and thermal coefficients. We calibrated each of the thermometers on all the devices. The calibrations showed a very good repeatability before and after heat transfer experiments. The calibration curves of each thermometer were plotted and fitting equations were obtained.

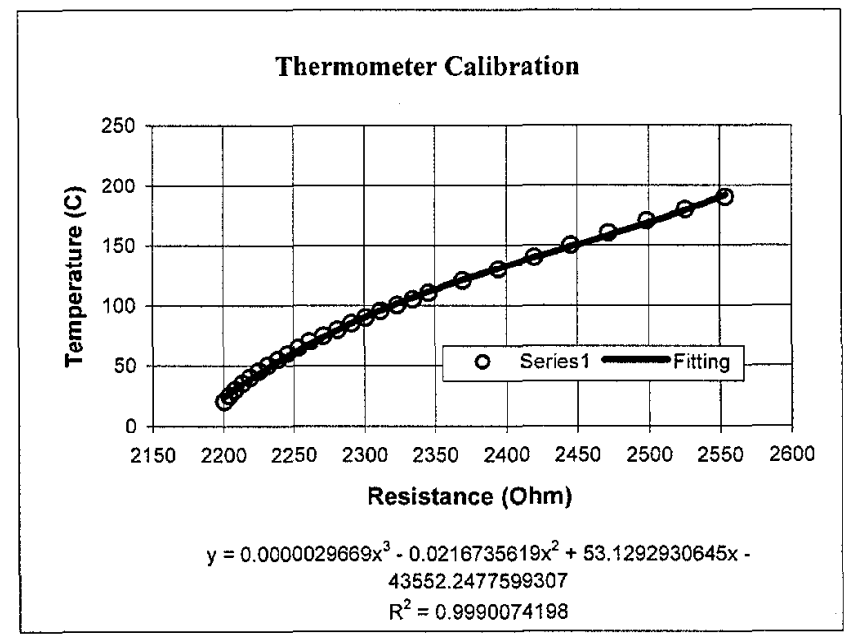

Figure 7. Calibration of a typical thermometer. We have seen resistance variations of $5-10 \%$ in the same wafer, so all thermometers were individually calibrated. Repeat calibrations on resistors after use indicated variations less than $0.2 \%$.

The first phase of the experiments was single-phase measurements. Figure 8 shows the measured and simulated pressure drops in the microchannels for various flow rates. The simulation model in these data is a simple laminar flow pressure 
drop relation with a constant friction factor (sec Equation (1)). The pressure drop data agree reasonably well with the fullydeveloped laminar flow model, supporting the use of the analogous fully-developed laminar heat transfer model, in which the Nusselt number is constant and the convection coefficient is independent of the flow velocity. Because the heat flux into the fluid varies along the length of the channel, due to conduction in the silicon, the use of a constant convection coefficient is not precisely correct. However, the error due to this approximation is small compared to the uncertainty in the measured temperature data.

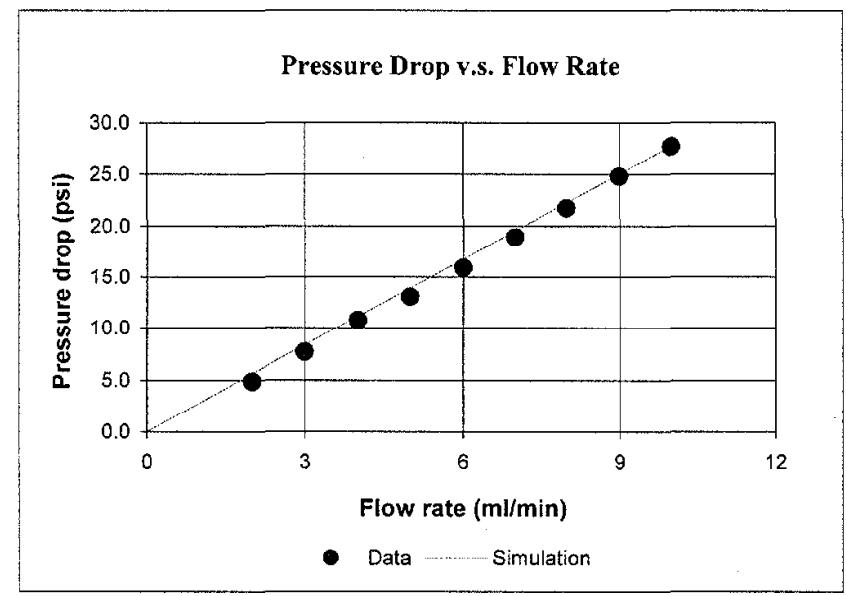

Figure 8. Pressure drop along the microchannels of device No. 4, a Type 1 device. This figure shows the measured and simulated pressure drop along the microchannels as a function of water flow rate at room temperature. A simple laminar flow model described in Equation (1) with constant friction factor accurately describes this data. Although pressure drop seems proportional to flow velocity squared in Equation (1), it is actually linearly proportional to flow velocity (or flow rate) because Reynolds number is also proportional to flow velocity.

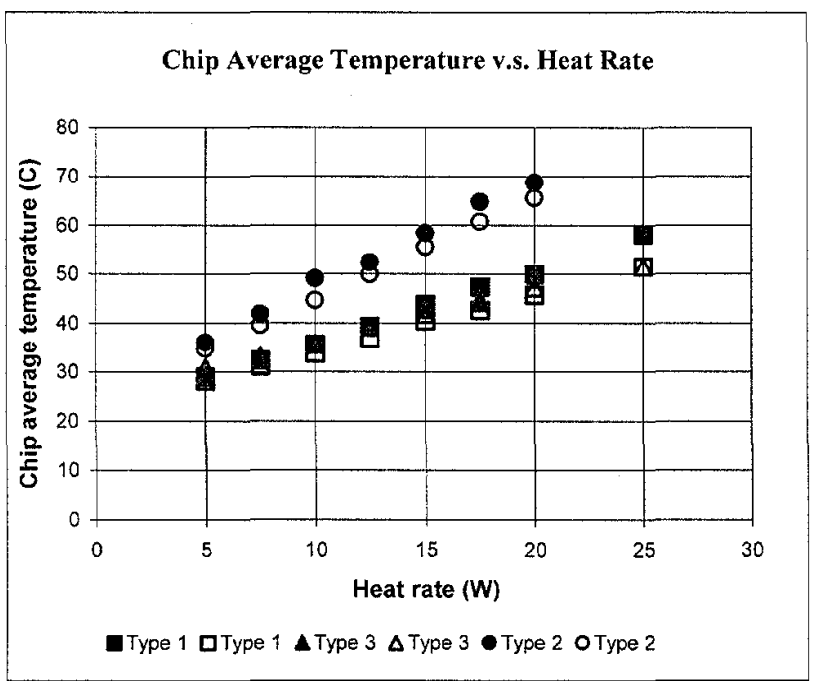

Figure 9. Chip average temperature as a function of heat rate for six devices of three types. As shown in Table 1. Type 1 and Type 3 have an effective cooling area of $4 \mathrm{~cm}^{2}$, with different size and number of microchannels, but similar entire convection area; Type 2 has an effective cooling area of $2 \mathrm{~cm}^{2}$. Type 1 and Type 3 devices were tested under $10 \mathrm{ml} / \mathrm{min}$ flow rate, while $5 \mathrm{ml} / \mathrm{min}$ for Type 2. Since Type 2 has a lower flow rate and less cooling area, the chip temperature rise is higher than Type I and Type 3 at the same heat rate. All trend lines extrapolate to the room temperature 22 C for zero heat input.

Next, we measured chip temperature as a function of heating rate for the three devices for the single-phase flow, as shown in Figure 9. In accordance with Equation (2) and (3), under a fixed mass flow rate, the average chip temperature linearly increases with the heat rate. $25 \mathrm{~W}$ of heat removal rate at $5-10 \mathrm{ml} / \mathrm{min}$ flow rate yields up to $50 \mathrm{C}$ average chip temperature rise.

Figure 10 shows the average chip temperature as a function of water flow rate for a fixed heat rate of $25 \mathrm{~W}$. Under singlephase flow, the chip temperature varies linearly with the inverse of the flow rate, according to Equations (2) and (3). This simple statement of the dependence neglects losses due to convection and radiation from the chip surface and into the fixture.

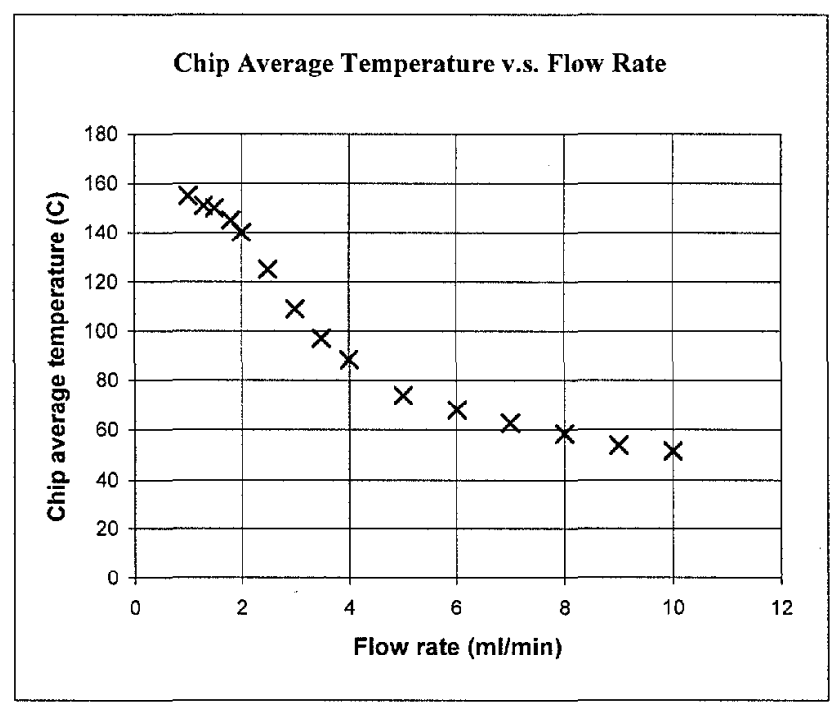

Figure 10. The Chip average temperature as a function of flow rate below $10 \mathrm{ml} / \mathrm{min}$ for a fixed heating power of $25 \mathrm{~W}$. Device No. 4 of Type 1 was tested as flow rate was reduced from 10 $\mathrm{ml} / \mathrm{min}$ to lower values, and boiling was observed at flow rates below $3 \mathrm{ml} / \mathrm{min}$ (as in Figure 10). After the onset of boiling, the chip temperature increases faster.

Figure 11 is an image of water boiling in microchannels with a hydraulic diameter of $55 \mu \mathrm{m}$. An interesting fact is, while the resistance readout of thermometers was quite stable in singlephase experiments, we observed resistance variations corresponding to 1-3 $\mathrm{C}$ after the onset of boiling. The formation of bubbles in these microchannels dramatically alters the fluid flow and heat transfer. The chip temperature change after the onset of boiling is plotted in Figure 10 together with single-phase flows. For this case the dependence of the chip temperature on the flow rate is increased, which indicates that the onset of boiling has substantially decreased the heat transfer coefficient in portions of the channels. Dry-out in the downstream portions of the channels is believed to be responsible for this decrease, which causes the temperature rise to increase substantially compared that for fully single-phase convection. This experiment did not resolve a diminished sensitivity of the temperature to the flow rate, which was expected at the onset of boiling before dry-out. 


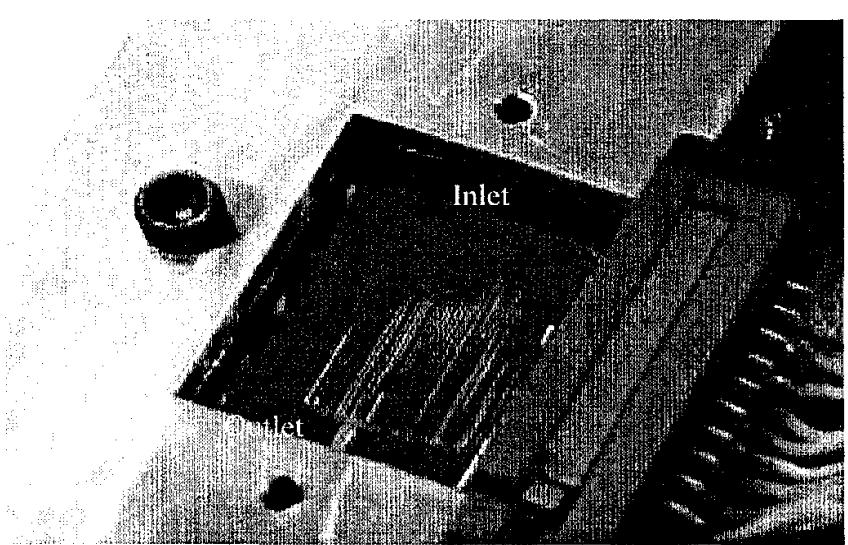

Figure 11. A close-up of water boiling in the microchannels with a hydraulic diameter of $55 \mu \mathrm{m}$. The shiny lines in the cooling area are where the bubbles are formed and move through the chip from the inlet to the outlet. Since there is a temperature distribution on the silicon substrate, the entire cooling area does not boil at the same time. Bubbles generate at the exit manifold of channels first, then the origin of the bubble line gradually moves to the entrance manifold in accordance with the local substrate temperature rise.

However, we still believe that the rate of chip temperature rise should be slowed down at the moment of boiling starts but before the dry-out occurs. Using the same device, we fixed the flow rate at $1 \mathrm{ml} / \mathrm{min}$, carefully adjusted the heat input rate and monitored the four temperature readouts. The fixture was placed under a microscope in order to detect the bubble formation.

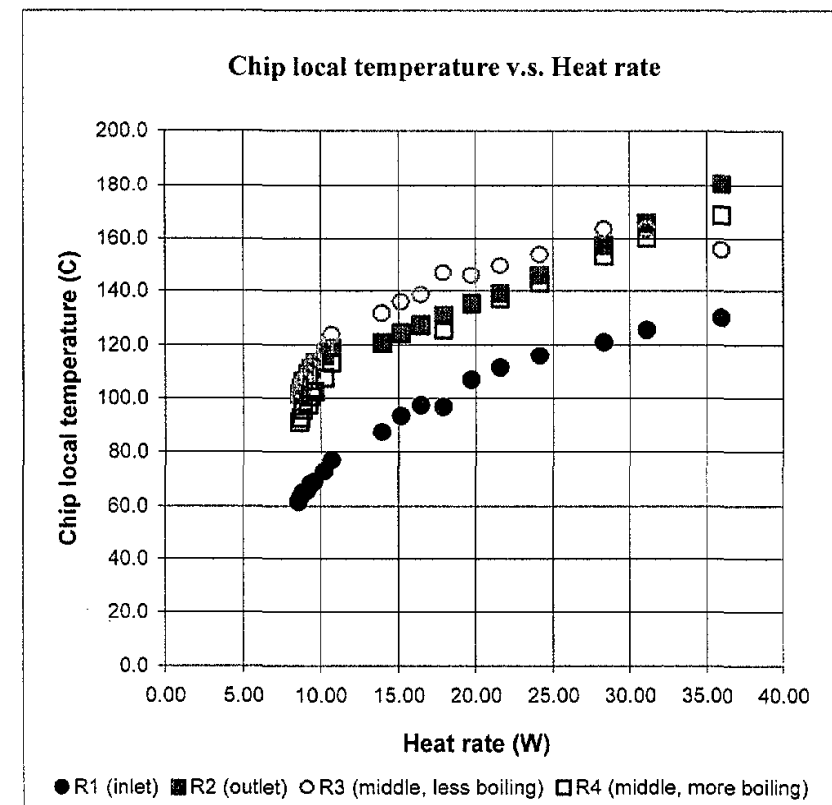

Figure 12. Boiling curve under a constant flow rate of $1 \mathrm{ml} / \mathrm{min}$. Device No. 4 was tested for phase change in the microchannels. The temperature readouts of the thermometers are no longer as stable as in the single-phase flow. The local temperature fluctuation is closely related to hubble generation.

Figure 12 plots the four temperature readouts as a function of heat removal rate. Local temperatures are plotted individually because spatially averaged temperature may dampen any significant fluctuation caused by bubble generation. Each of the four curves shows a clear slope change after the onset of boiling. The increase rate of chip temperature is slowed down by a factor of 5-10 under two-phase flow regime. We also noticed a local temperature drop of about $5 \mathrm{C}$ at the outlet when the first bubble formed in one of the microchannels.

Because of the density difference between liquid and gas phase and the associated bulk accelerations of the bulk flow, a significant change in pressure drop after boiling begins can be expected. Figure 13 is the pressure readout at the inlet when the flow rate is fixed at $1 \mathrm{ml} / \mathrm{min}$ and the heat rate increases from 0 to $35 \mathrm{~W}$. In the single-phase flow regime, the pressure drop decreases corresponding to the decrease of water viscosity at higher temperatures. However, after the onset of boiling, the pressure drop increases dramatically due to rapid vaporization.

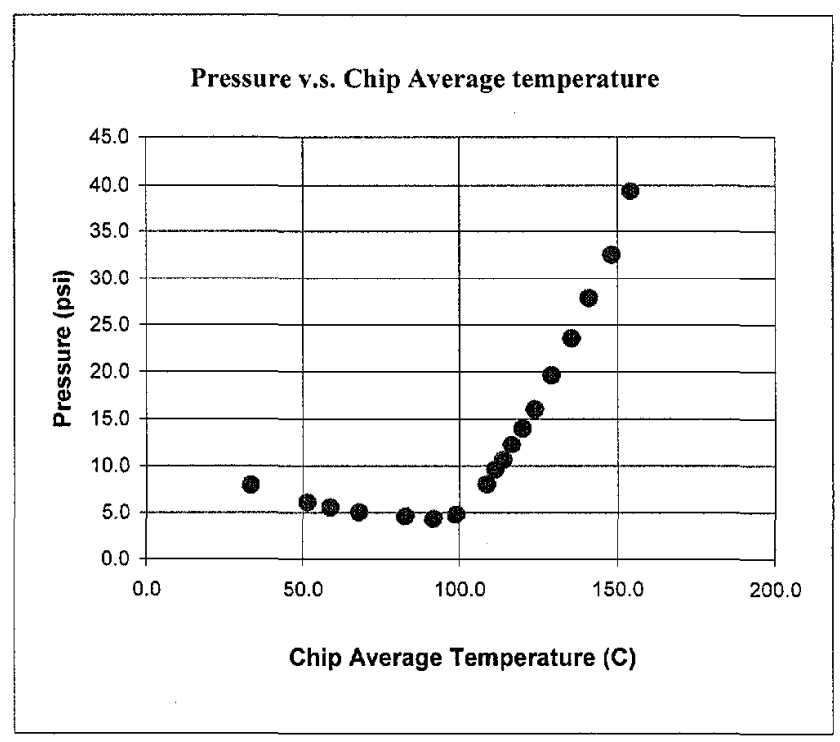

Figure 13. Inlet pressure change from single-phase to two-phase flow. Testing condition is the same as in Figure 12. The pressure drop as well as the flow conditions along the microchannels can vary dramatically because of the property difference between water and vapor. At a fixed $1 \mathrm{ml} / \mathrm{min}$ flow rate, the Reynolds number in the liquid phase is as low as 5.8, while the flow velocity is $0.1 \mathrm{~m} / \mathrm{s}$. If the fully developed boiling state is reached (with the quality equal to 1 ), the vapor velocity in the microchannels can be as high as $156 \mathrm{~m} / \mathrm{s}$.

\section{DISCUSSION}

As shown in Figure 11, the boiling is not uniform across the channels. This may be caused by a non-uniform heating or nonuniform flow distribution. The non-uniform heating may be caused by the breaking down of $\mathrm{PN}$ junctions and by conduction in the silicon. Our experiments show that the heaters require a long annealing and/or a low background doping level in order to work reliably under high power input. The reason is that the resistors are isolated by $\mathrm{PN}$ junctions that can break down at a certain voltage threshold. Both a long annealing and a lightly doped substrate help to increase this break-down threshold. On the other hand, however, this also indicates that more work is 
needed to establish stable two-phase, sub-critical heat flux convection.

A large group of microchannels with a large cooling area is probably best for an actual microchannel heat exchanger application, but not for certain heat transfer experiments. As a general guide, the total convective thermal resistance can be significantly reduced by increasing the number of microchannels, while the large cooling area with distributed heaters makes it more difficult to maintain a uniform heating condition. In addition, it is also very difficult to evenly distribute the fluid into the individual microchannels. We have observed a roughly parabolic flow profile across the microchannels with our current inlet manifold design, which gives a higher flow rate to the middle channels. As an example, a single channel or a small group of microchannels is a better design for critical heat flux study.

The manifold design can also influence the boiling condition in the microchannels. In this design, the two " $\mathrm{T}$ " shaped channels are used as fluid inlet and outlet. Since the manifold has a much larger surface area than the microchannels in the effective cooling area, the bubbles tend to form in the manifold. However, boiling in the manifold can be reduced by increasing the thermal resistance of the manifold.

We also notice the temperature increase of the fixture during the experiments, indicating a heat loss from the fixture. The current fixture is made of aluminum, which has a very high thermal conductivity. To reduce the heat loss from the fixture, we can choose materials with low thermal conductivity, reduce the length of the internal flow channels, or place thermal isolations in the device itself-for example, cutting trenches in the silicon chip.

\section{CONCLUSIONS}

This work shows that micromachined thermometers and heaters can aid with the study of single and two-phase convection in microchannels. With our current microchannel test systems, we have successfully observed phase change in microchannels as well as conducted detailed flow and heat transfer experiments. With DRIE technique, we are able to control the aspect ratio of the microchannels. These implanted resistors provide a reliable method to control the heat input rate as well as to measure the local temperature change. We measured up to $50 \mathrm{C}$ average chip temperature rise, under DI water single-phase convection at 5-10 $\mathrm{ml} / \mathrm{min}$ flow rate at $25 \mathrm{~W}$ heat removal rate. We have also observed variations in the resistances of the thermometers as boiling begins in these microchannels. Temperature variations of up to $3 \mathrm{C}$ at frequencies of $1 \mathrm{~Hz}$ and faster have been observed, indicating that dynamic thermal measurements are possible in these structures.

Ongoing research is studying nucleation in microchannels and the relationship with channel wall roughness and the critical heat flux. Through these experiments, we aim to construct a more accurate model for the design of stable two-phase microchannel heat exchangers for integrated circuits.

\section{ACKNOWLEGMENTS}

This work is supported by DARPA HERETIC Program under DARPA Contract F33615-99-C-1442, Stanford Graduate Fellowships (first author), and the SRC Fellowship (fourth author). The project made use of the National Nanofabrication
Users Nctwork facilitics funded by the National Science Foundation under award number ECS-9731294.

\section{REFERENCES}

1. D. B. Tuckerman, and R. F. W. Pease, "High-Performance Heat Sinking for VLSI", IEEE Electron Device Letters, Vol. EDL2, No. 5, pp126 (1981).

2. V.K. Samalam, "Convective Heat Transfer in Microchannels", Journal of Electronic Materials, Vol. 18, No. 5, pp611 (1989).

3. R. W. Knight, D. J. Hall, J. S. Goodling, and R. C. Jaeger, "Heat Sink Optimization with Application to Microchannels", IEEE Transactions on Components, Hybrids, and Manufacturing Technology, Vol. 15, No. 5, pp832 (1992).

4. X. F. Peng, H. Y. Hu, and B. X. Wang, "Flow Boiling through V-Shaped Microchannels", Experimental Heat Transfer, Vol. 11, pp87 (1998).

5. L. Jiang, and M. Wong, "Phase Change in Microchannel Heat Sinks with Integrated Temperature Sensors", Journal of MEMS, Vol. 8, No. 4, pp358 (1999).

6. F. M. White, "Fluid Mechanics ( $4^{\text {th }}$ Edition)", McGraw-Hill Companies, Inc., ISBN 0-07-069716-7, (1999). 